\title{
Synthesis, X-ray and NMR Studies on Palladium BINAP Complexes Containing Oxazolidinone and Acetylacetonate Anions.
}

\author{
Devendrababu Nama, Paul S. Pregosin* \\ Laboratory of Inorganic Chemistry, ETHZ, 8093 Zürich, Switzerland, \\ Alberto Albinati and Silvia Rizzato \\ Department of Structural Chemistry (DCSSI), University of Milan, 20133 Milan, \\ Italy
}

\section{Supporting information.}

The slope of the lines, $\mathrm{m}$, were obtained by plotting the decrease in the natural logarithm of the signal intensity vs $\mathrm{G}^{2}$.

$$
\ln \left(\frac{I}{I_{o}}\right)=-(\gamma \mathrm{d})^{2} G^{2}\left(\mathrm{D}-\frac{\mathrm{d}}{3}\right) D
$$

$G=$ gradient strength, $\Delta=$ delay between the midpoints of the gradients, $D=$ diffusion coefficient, $\delta=$ gradient length

The diffusion coefficients reported were determined using the diffusion coefficient of $\mathrm{HDO}$ in $\mathrm{D}_{2} \mathrm{O}$ as a reference $\left(\mathrm{D}_{\mathrm{HDO}}=1.9 \times 10^{-9} \mathrm{~m}^{2} \mathrm{~s}^{-1}\right.$ ), which afforded a slope of $2.005 \times 10^{-4}$. The data obtained were used to calculate the $D$ values of the samples, according to

$$
D=\frac{m_{o b s} \times D_{H D O}}{m_{H D O}}
$$

All the reported $D$ values are derived from lines that have correlation coefficient of $>0.99$. 
As an example, both ${ }^{1} \mathrm{H}$ and ${ }^{19} \mathrm{~F}$ diffusion NMR spectra and graph showing intensity of NMR signal versus gradient strength for complex $12 a$ in chloroform- $d_{1}$ (2mM).

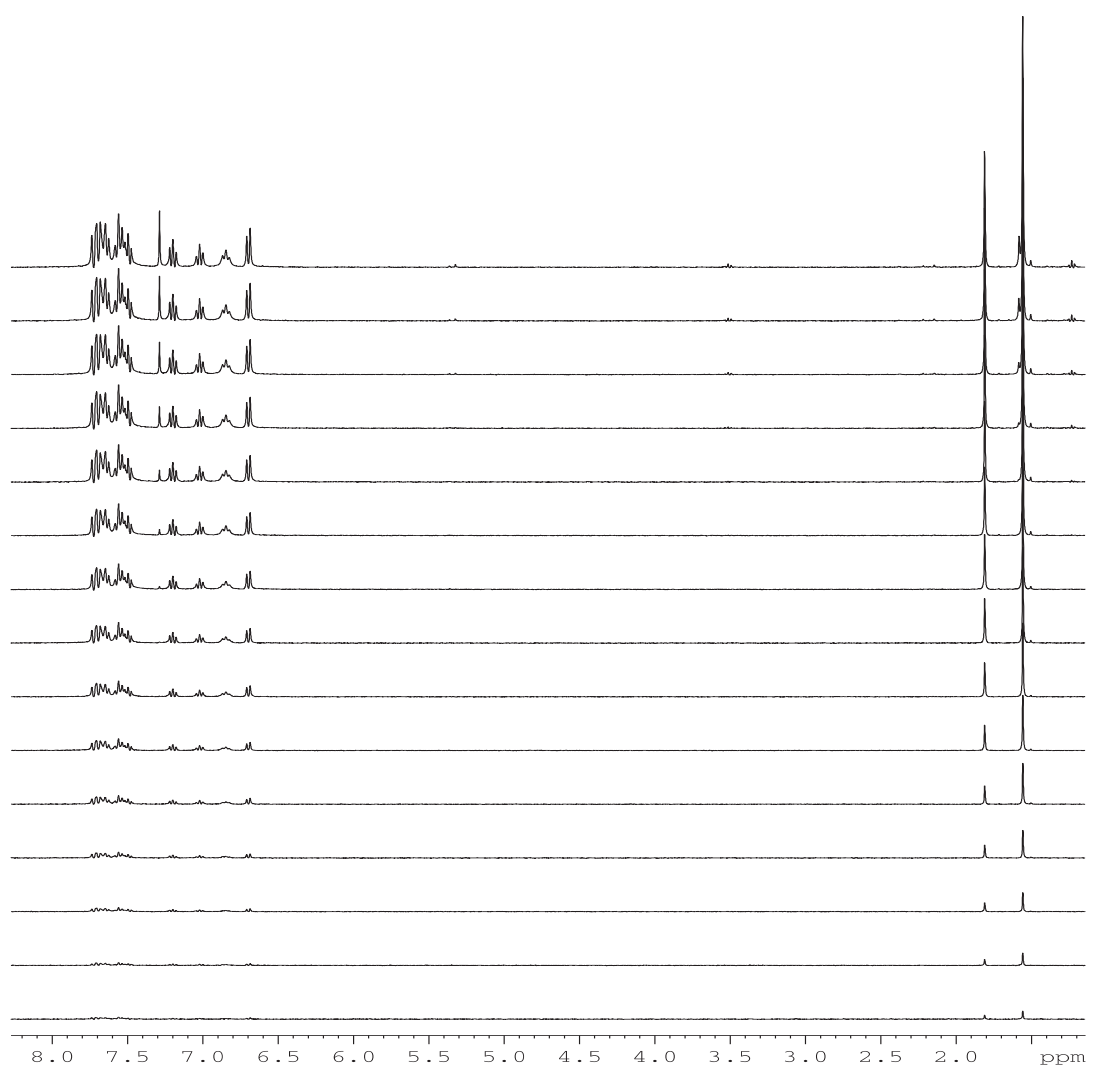

Fig S1: ${ }^{1} \mathrm{H}$ diffusion NMR spectra of complex 12a with varying gradient strengths (4\% to $60 \%)$.

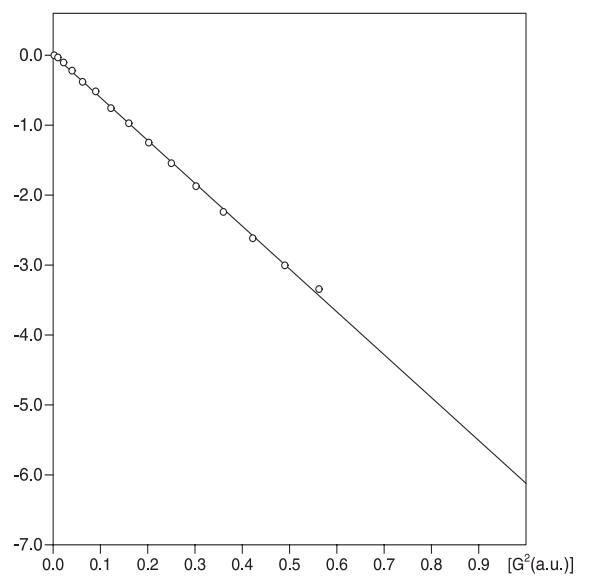

Fig S2: Graph showing intensity vs gradient strength for complex 12a for cation $\left({ }^{1} \mathrm{H}\right)$.

$\mathrm{m}_{\mathrm{H}}=6.14 \times 10^{-4}$

$\mathrm{m}_{\mathrm{HDO}}=2.005 \times 10^{-4}$

$\mathrm{D}=5.82 \times 10^{-10} \mathrm{~m}^{2} \mathrm{~s}^{-1}$ 


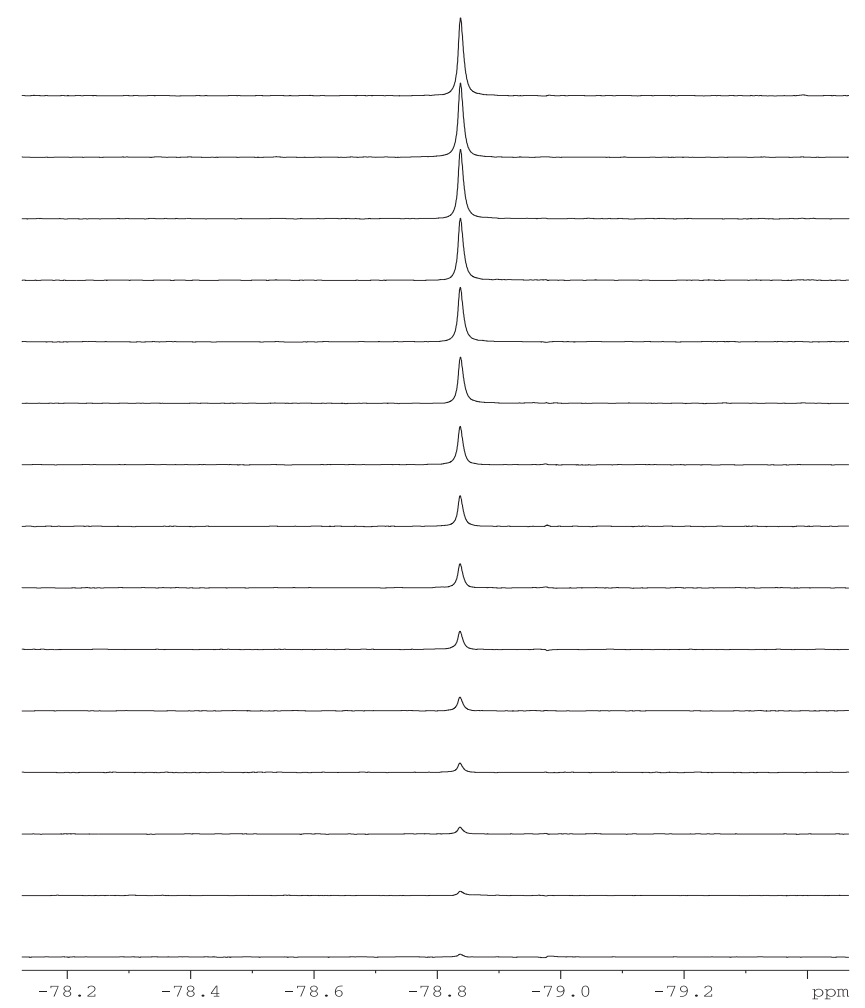

Fig S3: ${ }^{19} \mathrm{~F}$ diffusion NMR spectra of complex 12a with varying gradient strengths (4\% to $60 \%)$.

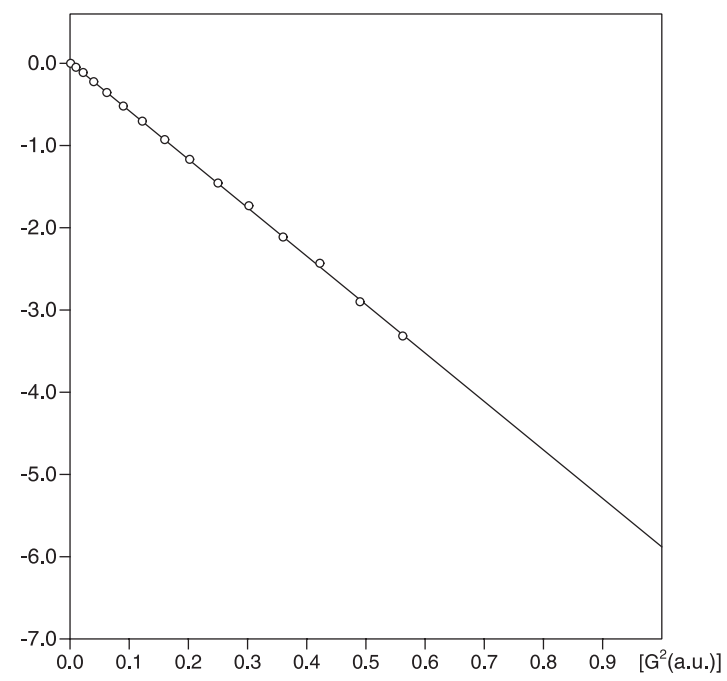

Fig S4: Graph showing intensity vs gradient strength for complex 12a for anion $\left({ }^{19} \mathrm{~F}\right)$.

$$
m_{F}=5.89 \times 10^{-4}
$$


$m_{F}$ in terms of $m_{H}, m_{H}=6.65 \times 10^{-4}$

$$
\begin{aligned}
& m_{H D O}=2.005 \times 10^{-4} \\
& D=6.30 \times 10^{-10} \mathrm{~m}^{2} \mathrm{~s}^{-1}
\end{aligned}
$$

